\title{
RIO TAMANDUATEÍ - NASCENTE À FOZ: PERCEPÇÕES DA PAISAGEM E PROCESSOS PARTICIPATIVOS
}

\author{
TAMANDUATEI RIVER - SPRING TO ITS ESTUARY: \\ LANDSCAPES 'S PERCEPTIONS AND PARTICIPATORY PROCESS
}

RAMALHO, Daniela

Mestre em Paisagismo - FAU USP. E-mail: danielaramalho@gmail.com

\section{RESUMO}

Este artigo foi baseado na dissertação de mestrado defendida na FAU-USP e busca a contribuição do arquiteto paisagista na preservação das Paisagens Fluviais Urbanas.

A metodologia adotada foi a pesquisa-ação, a qual norteou um embasamento teórico e empírico que resultou na aplicação de oficinas em representantes das comunidades envolvidas, além de representantes dos setores públicos, privados, não-governamentais e instituições de ensino.

Os produtos resultantes das oficinas foram dois projetos de paisagismo em áreas públicas e um vídeo documentário com o registro de todo o processo participativo de percepção e ação na preservação das paisagens fluviais da nascente à foz do Rio Tamanduateí.

Palavras-chave: Arquitetura paisagística, urbanismo, recursos hídricos, água, cidadania, meio ambiente, participação comunitária, interdisciplinaridade, paisagens fluviais, pesquisa-ação.

\begin{abstract}
This article was based on a dissertation of PHD - thesis submitted to evaluation at University of Architecture and Urbanism of São Paulo State. This proposes to analyze the landscape architect's contribution to the preservation of Fluvial Landscape.

The methodology applied was the "Research-Action", witch inspired a theorical and empiric thesis that resulted in several work sections with community's leaders, members of public and private institutions and educational and non governmental organizations.

The gain products were two landscape projects in public areas and a documentary video that registrate the whole process of participation, perception and action looking forward the preservation of Tamanduatey's River spring to its estuary.
\end{abstract}

Key words: Landscape architecture, urbanism, water resources, water, citizenship, environment, comunity envolvment, multisubject, fluvial landscape, research-action.

\section{Introdução}

Os rios foram essenciais para a RMSP (Região Metropolitana de São Paulo), mas as Paisagens Fluviais têm sido gradativamente desfiguradas nas áreas urbanas, os recursos hídricos muitas vezes têm se tornado apenas recursos econômicos e seus aspectos culturais, históricos e sócioambientais têm sido ignorados.

O Rio Anhembi - Rio das aves anhumas (Rio Tietê), o Rio Jurubatuba - Rio dos Jerivás (Rio Pinheiros) e o Rio Piratininga - Rio dos peixes secos (Rio Tamanduateí)' são percebidos apenas por uma pequena parcela da sociedade, pois suas margens se tornaram grandes avenidas e corredores expressos. 
Acreditamos que restaurar tais paisagens é inviável, mas potencializá-las é possível. Para tanto, esse estudo procurou a contribuição da arquitetura numa pesquisa-ação capaz de estimular a percepção, sensibilização e apropriação dos usuários em relação a essas paisagens.

\section{Estruturação da pesquisa}

A temática da pesquisa teve como finalidade buscar a contribuição do arquiteto na defesa das paisagens fluviais urbanas por meio de processos participativos no Rio Tamanduateí.

A justificativa da abordagem teve como diferencial, o recorte da Paisagem e seus desdobramentos sob uma ótica sensível à natureza urbana e ao homem que a habita, de forma que esse estudo fosse útil à sociedade. A escolha do Rio Tamanduateí ocorreu devido à sua importância histórica e a atual desfiguração de sua paisagem.

A problemática adotada foi considerar esse estudo de uma forma abrangente e não fragmentada. Procuramos não considerar o objeto de estudo a partir de divisões político-administrativas, eixos ou apenas sua bacia hidrográfica. Consideramos também as lideranças sociais que influenciassem nessas paisagens e destacamos áreas residuais despercebidas com grande potencial social e paisagístico.

O objetivo dessa dissertação foi buscar ferramentas de sensibilização que possibilitassem a percepção da paisagem e promovessem uma gestão participativa.

Aplicamos a metodologia da pesquisa-ação ${ }^{2}$ a fim de buscarmos a troca de saberes entre os participantes, além de estimularmos um processo participativo que almeje a autonomia da gestão e a construção da cidadania no Brasil.

\section{Desenvolvimento da pesquisa}

Essa pesquisa buscou a caracterização da problemática e se aprofundou em alguns aspectos pertinentes para o desenvolvimento do estudo.

A importância da água e dos rios na história das cidades, bem como a globalização e a distribuição da água doce no mundo são imprescindíveis para a compreensão da problemática. $A$ partir daí, constatamos muitas conseqüências decorrentes da má gestão dos recursos hídricos, mas também algumas referências na busca pela preservação das paisagens fluviais, como por exemplo, no Japão e na Alemanha. No caso da Grande São Paulo, observamos a nítida presença das águas em sua formação, porém seguida de um processo de canalização e supressão de suas matas ciliares.

Num primeiro momento acreditamos necessária a discussão sobre a construção das paisagens fluviais na RMSP. Para tanto, podemos questionar os principais projetos e políticas públicas ao longo dos rios como: Projeto Pomar no Rio Pinheiros, Projeto Tietê no Rio Tietê e o antigo "FuraFila" (atual "Corredor Expresso") no Rio Tamanduateí, dentre outros. Além disso, podemos discutir ainda o recorte da unidade de planejamento, a qual seja capaz de respeitar as necessidades ambientais e sociais que denominamos de "Unidades de Paisagem" e "Microunidades de Paisagem". Isto se deve ao fato de acreditarmos que não bastam apenas atuações na paisagem em escala metropolitana, consideramos também necessárias as atuações em escala local para que seja possível um processo de vínculo do usuário a esses lugares.

100 Outro aspecto significativo é focarmos a importância dos processos participativos. A compreensão de conceitos como espaço, paisagem e lugar contribuem para a construção de uma paisagem qualificada, dotada de identidade e vínculos com seus usuários. Assim como, os conceitos de percepção, sensibilização e apropriação contribuem para a preservação das paisagens fluviais e para as expectativas desses usuários. Esse processo necessita de uma gestão participativa 
que podemos conceituar em diversos graus de atuação. A crise do modernismo e sua relação com a tendência à gestão participativa podem ser observadas por meio da análise de diversos processos participativos ao longo da história.

Por fim, procuramos uma metodologia que atendesse a essa tendência e suprisse às necessidades de gestões participativas. Dessa forma, aplicamos a pesquisa-ação no objeto de estudo, com a participação das comunidades e de representantes de diversos setores. Abordamos a contribuição do arquiteto na "pedagogia da paisagem" ${ }^{3}$, conceito defendido pela Profa. Dra. Catharina Lima, e sua participação na gestão de processos participativos. Este último momento descreveu um breve resumo sobre cada comunidade envolvida e registrou as atividades desenvolvidas durante três oficinas aplicadas e denominadas como Oficina do "Ver", "Sentir" e "Agir".

\section{Pesquisa-ação}

Consideramos necessário juntar a pesquisa à ação, coletar dados, trocar saberes, mas, sobretudo, devolver este material desenvolvido a tantas mãos, aos seus "co-autores" - a própria população.

Esse estudo pretendeu avançar na discussão da metodologia da pesquisa-ação e sua aplicabilidade para a problemática escolhida. Segundo Michel Thiollent, a metodologia da pesquisa social tem o intuito de "promover aplicações criativas em várias áreas específicas e ensejar a geração e a difusão de conhecimentos úteis a resolução de problemas do mundo real". ${ }^{4}$

○ "porquê" se dá pelo fato de não ser uma pesquisa descritiva comum e sim apenas um ponto de partida para o trabalho de investigação e de ação.

○ "como" é feito com a captação da informação empírica por meio de um caráter coletivo do processo de investigação.

A metodologia aplicada nas oficinas usou como recurso principal a exploração dos córregos ocultos e o estudo do meio. Recorremos ao conceito da "Pedagogia da Paisagem" que é "um processo através do qual a paisagem, como um texto, informa; a partir dessa percepção capacita a instrumentalização das pessoas, possibilita um processo de conhecimento e prepara a sociedade para intervir nessa paisagem. A pedagogia da paisagem é a síntese do processo participativo no paisagismo" 5 .

Procuramos subsídios na pedagogia de Freinet e Paulo Freire, a fim de estabelecer uma relação intrínseca entre "arquiteto x usuário" e "professor x aluno", ao buscarmos uma atuação do arquiteto como mediador de processos participativos e ao procurarmos formas de qualificar os espaços públicos. Para Paulo Freire "Há uma pedagogicidade indiscutível na materialidade do espaço". 6

A seleção de "para quem" esse trabalho seria destinado foi feita por meio da amostragem intencional, de Thiollent, a qual destacamos importantes lideranças da comunidade, expressivos formadores de opinião, especialistas, representantes de ONGs, órgãos públicos, privados e instituições de ensino.

○ "quando" foi feito a partir da finalização da pesquisa teórica para que esta pudesse ser socializada com as comunidades envolvidas. Foram realizadas três oficinas em sábados subseqüentes.

\section{Objeto de estudo}

\section{Rio Tamanduateí - nascente à foz}

A importância da escolha pelo percurso integral do Rio Tamanduateí é o fato de buscarmos uma abordagem ampla de percepção da paisagem, que subsidie os diagnósticos e as propostas para os estudos de caso. 
Definimos a Bacia Hidrográfica do Tamanduateí como nossa Unidade de Paisagem. $\bigcirc$ Rio Tamanduateí percorre quatro municípios: Mauá, Santo André, São Caetano e São Paulo. Já ao considerarmos a Bacia do Alto Tamanduateí devemos acrescentar os municípios de São Bernardo do Campo e Diadema.

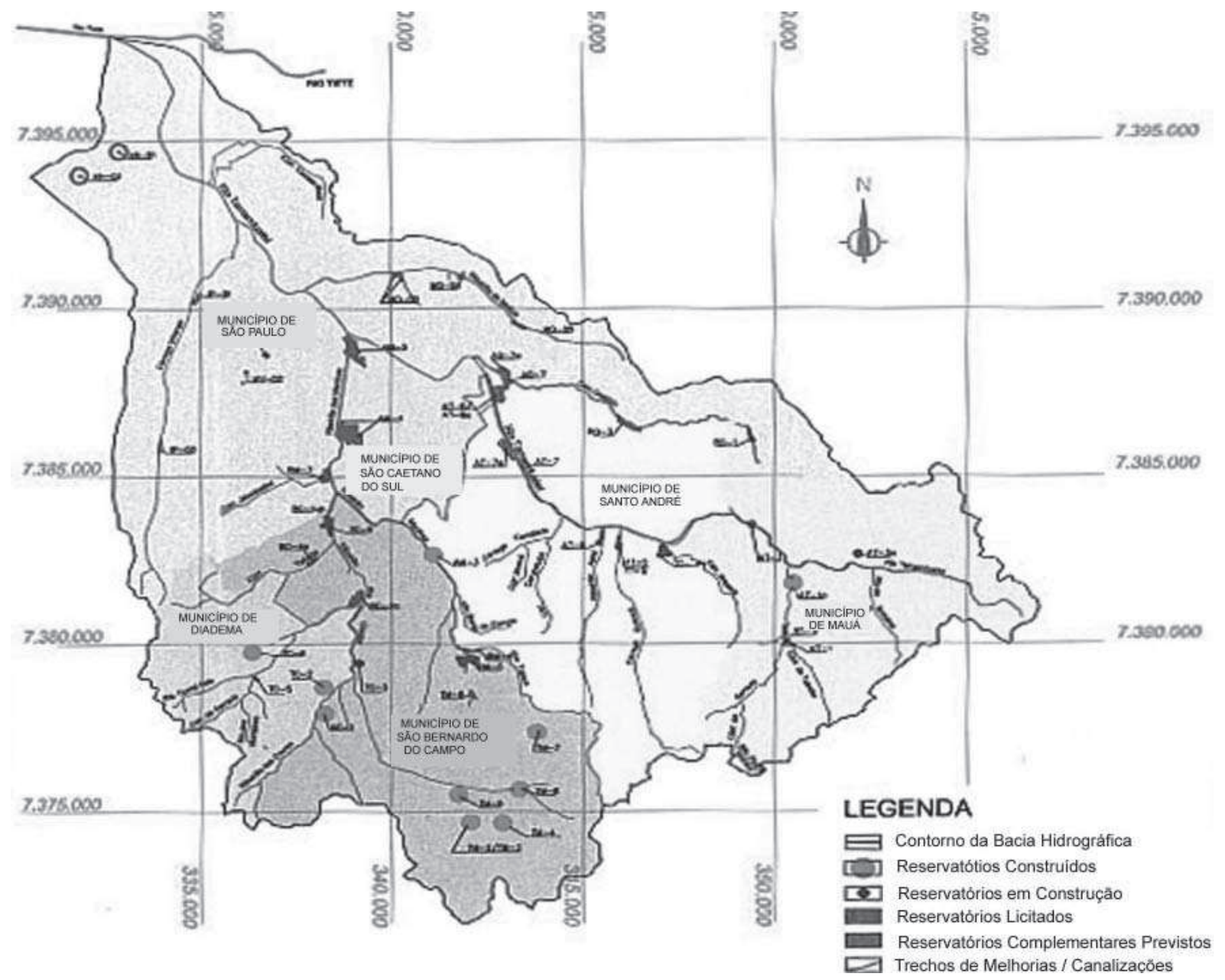

Figura 1: Bacia Tamanduateí

Fonte: SANTOS, Magda. Águas revoltas: A história das enchentes em Santo André, SEMASA, Prefeitura Municipal de Santo André, 2002

Contudo, muitos de seus afluentes, assim como outros da RMSP, se tornaram "Córregos Ocultos" 7 , termo utilizado pelo Prof. Dr. Vladimir Bartalini, devido à canalização e ocupação intensa de suas margens e de seu leito muitas vezes tamponado, o que possibilitou a implantação de diversas avenidas.

Dentre os principais afluentes, destacamos: Ribeirão dos Meninos (Av. Almirante Delamare, Av. Guido Aliberti e Avenida Lauro Gomes), Ribeirão da Moóca (Av. Luís Inácio de Anhaia Melo, Córrego do Oratório, Córrego Guarará (Av. Capitão Mario Toledo), Ribeirão Apiaí (Av. Firestone), além do Córrego Ipiranga, Ribeirão dos Couros, dentre outros.

Em conseqüência a essa equivocada ocupação, as áreas verdes diminuíram, as impermeabilizações aumentaram e o número de enchentes também. Para minimizar essa problemática, estão previstos 46 piscinões na Bacia do Alto Tietê, os quais são questionáveis, pois não resolvem o problema - apenas o amenizam - e violam a Paisagem Fluvial.

A nascente do Rio Tamanduateí se encontra em Mauá, na Gruta de Santa Luzia, sediada num Parque que abriga remanescentes de mata atlântica. Contudo, na saída desse Parque já presenciamos os primeiros sinais de polvição. Ainda em Mauá, acompanhamos a desfiguração 
da paisagem que se torna cada vez mais urbana, já com o uso de vias expressas nas margens do Rio. Em Santo André e São Caetano, a Av. Estado e inúmeras indústrias se destacam. Em São Paulo, a estrutura do antigo "Fura-Fila", atual "Corredor Expresso" sobreposto ao leito tamponado do Rio o torna ainda mais oculto e inacessível. A foz se encontra com o Rio Tietê, mas muitas vezes também passa despercebida pela maioria daqueles que transitam no ritmo frenético da Marginal Tietê.

\section{Estudos de caso}

Os Estudos de Caso que correspondem as Microunidades de Paisagem foram selecionados por se destacarem quanto à mobilização e iniciativa da comunidade pela preservação das Paisagens Fluviais, todos se localizam em Santo André.

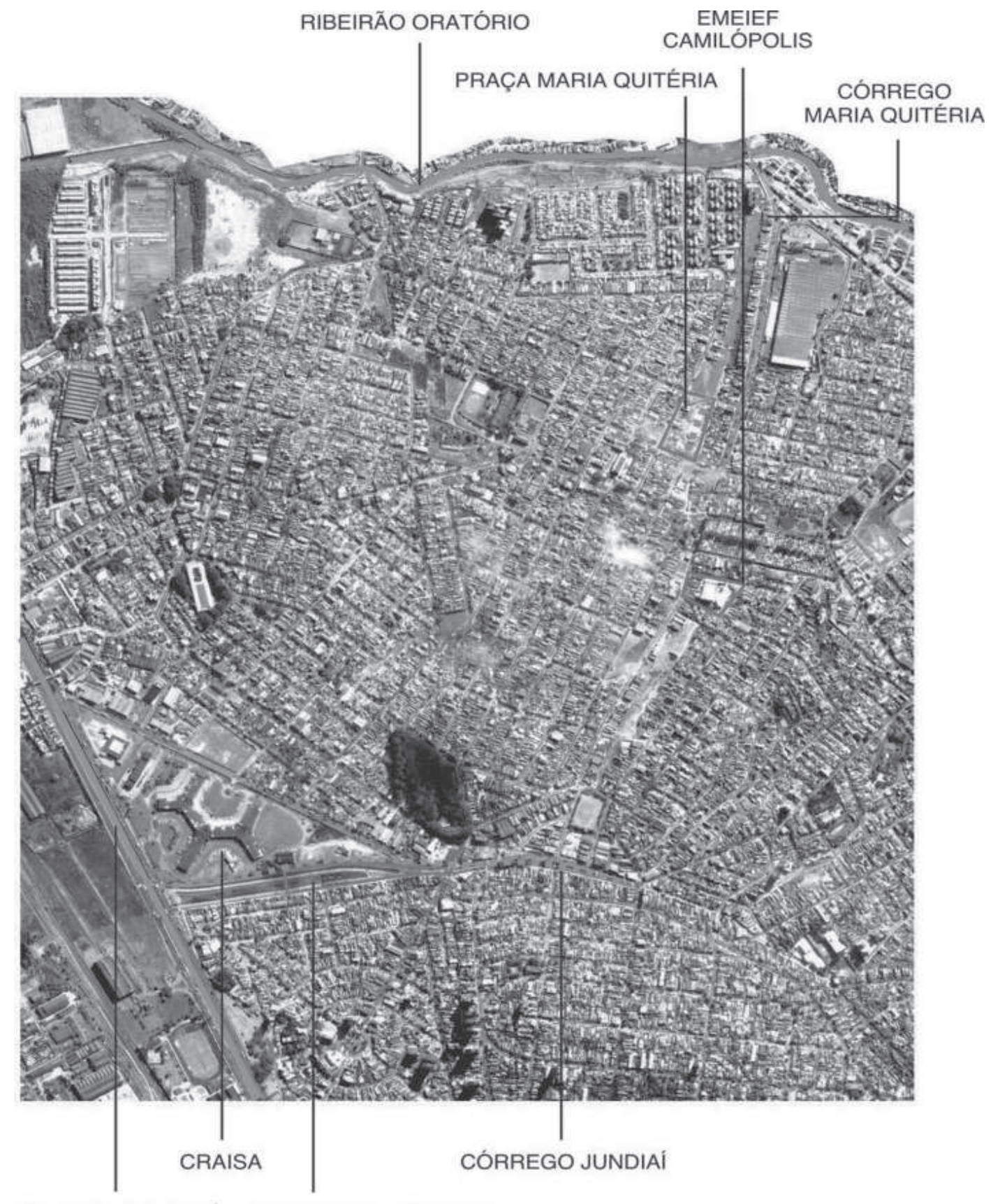

RIO TAMANDUATEI PESQUEIRO GIRASSOL

Figura 2: Foto aérea com a localização dos estudos de caso e o rio Tamanduateí

Fonte: Prefeitura Municipal de Santo André. Edição: Rodrigo Ramalho, Daniela Ramalho e Leonardo Loyolla, 2005 


\section{Praça Maria Quitéria}

Localizada junto ao Córrego Maria Quitéria foi selecionada por ter sido construída por sistema de mutirão numa parceria entre a Prefeitura de Santo André (orientação técnica e materiais de construção) e a comunidade local (mão-de-obra).

Executada em três anos, participaram deste mutirão principalmente mulheres e homens da terceira idade, sendo que alguns deles chegaram a lavar roupas no antigo riacho agora aterrado. Esta iniciativa da comunidade transformou a Praça em símbolo de orgulho e apropriação do espaço público, a ponto de desenharem sua paisagem no muro de uma das casas.

Contudo, após a inauguração, o Projeto que priorizou o caminho das águas e a incorporação de algumas nascentes, não se garantiu devido à falta de manutenção e à ocupação do espaço por novos visitantes que degradavam a área. Até o início das oficinas a Praça se encontrava sem manutenção e a comunidade local extremamente desmotivada.

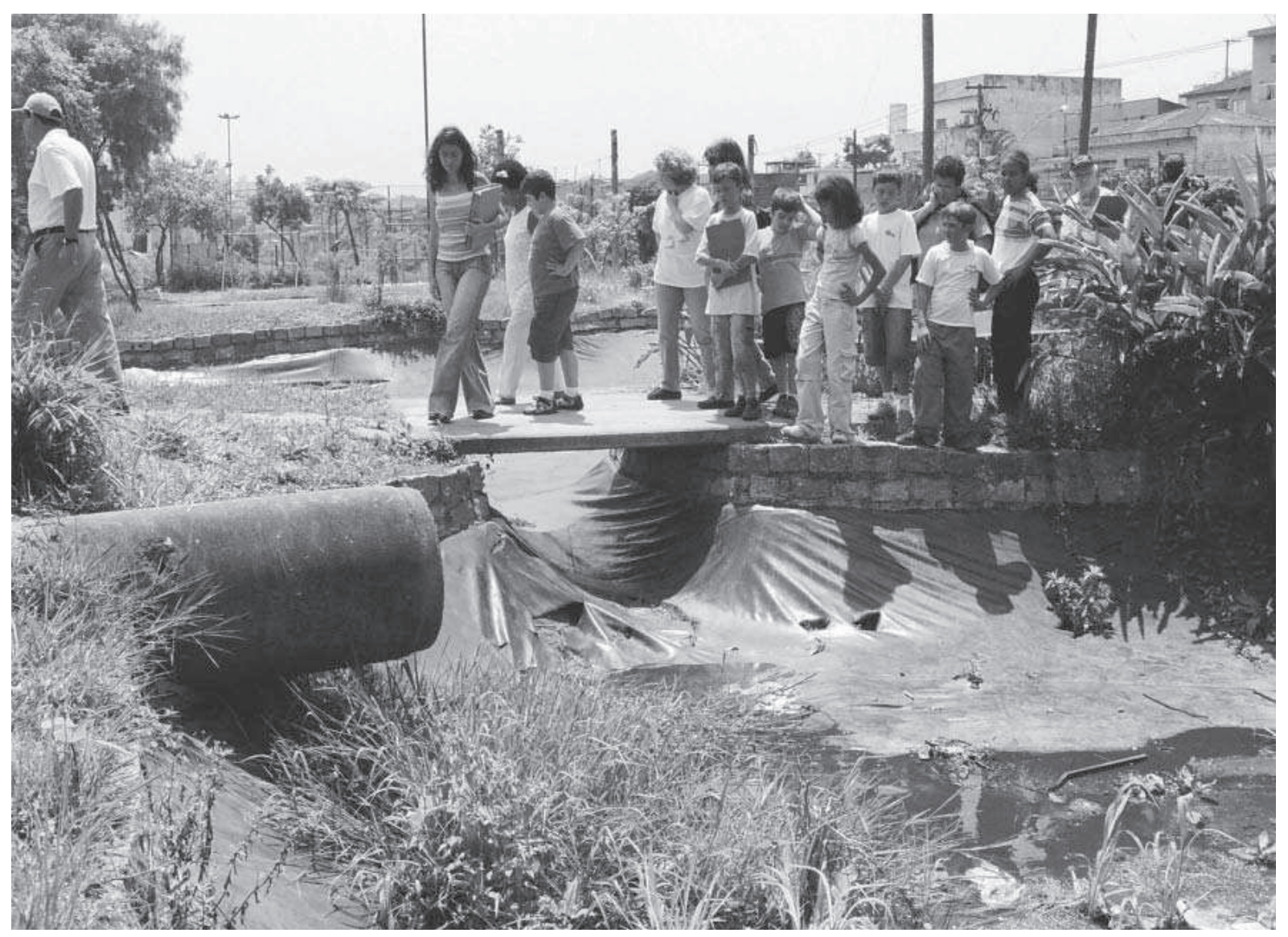

Figura 3: Praça Maria Quitéria.

Foto: Arquivo Daniela Ramalho, 2005

\section{Pesqueiro Girassol}

Localizado junto ao Córrego Jundiaí, este Pesqueiro foi destacado por se tratar de um espaço de lazer inusitado na região, já que está numa área de retenção de águas pluviais a menos de $1.000 \mathrm{~m}$ da Av. dos Estados. Essa pequena área não é normalmente notada, mas mostra que uma iniciativa da comunidade local pode potencializar os afluentes do Rio.

$104 \bigcirc$ "Pesque-e-solte" prova que o Rio Tamanduateí guarda ainda a calmaria do interior, atrai dezenas de usuários diariamente (principalmente idosos) que chegam de vários lugares da Grande São Paulo e, além disso, assegura abrigo para inúmeras espécies de plantas e animais, principalmente peixes e aves migratórias. 
Entretanto, a área, que se mantém graças à contribuição da comunidade e de empresários, peca pela falta de orientação técnica, por exemplo, com a construção de sanitários sem tratamento de esgoto e com a solicitação de doações de mudas de árvores não apropriadas para mata ciliar.

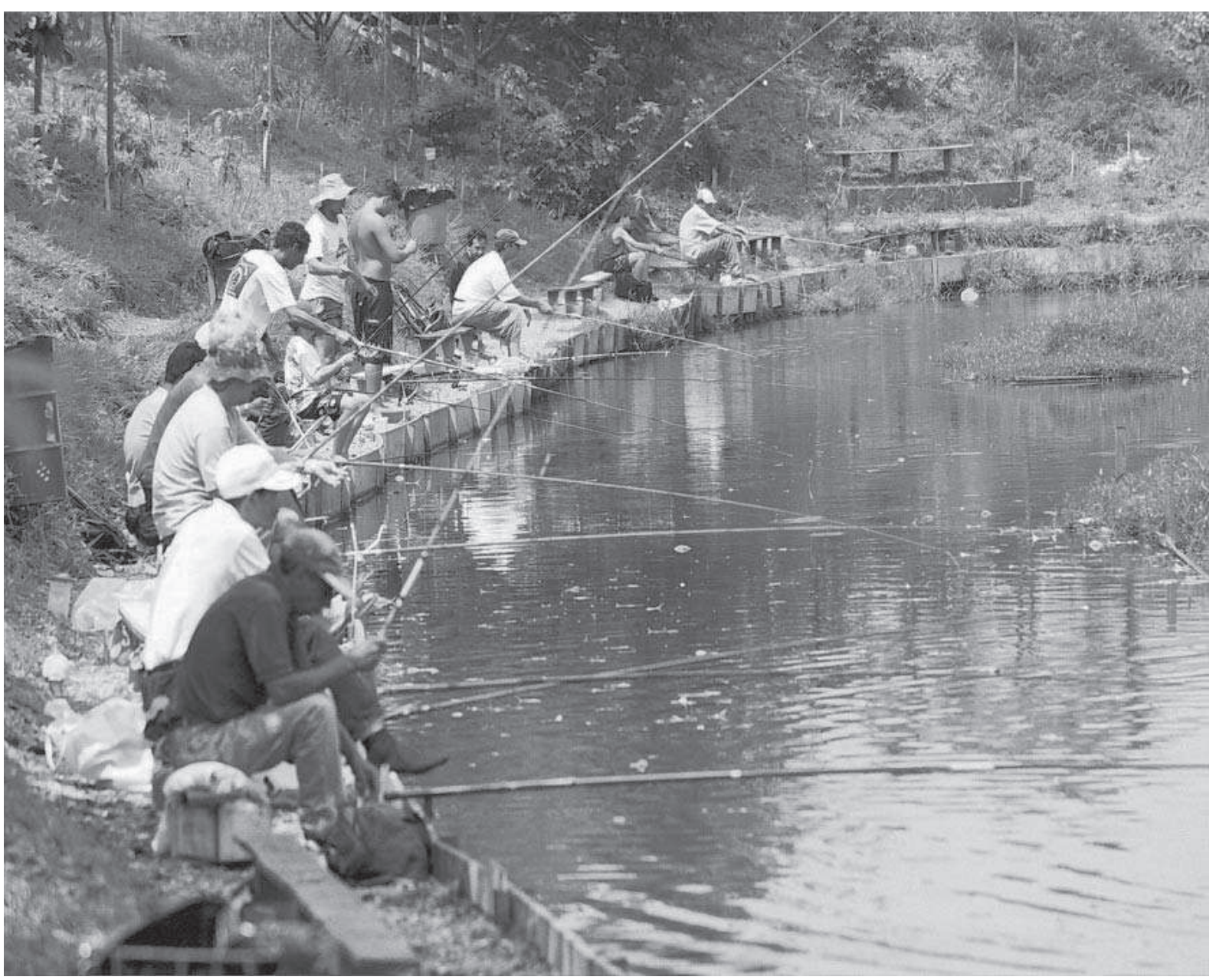

Figura 4: Pesqueiro Girassol. Foto:Arquivo Daniela Ramalho, 2005.

\section{EMEIEF Camilópolis}

A Escola está localizada no divisor de águas das duas microbacias que abrigam as áreas citadas acima e se destaca por aplicar na prática o conceito de Escola Aberta. A comunidade participa diretamente das atividades da Escola e mantém o Conselho de Pais e Alunos. Além disso, a Escola desenvolveu diversos trabalhos sobre a importância da água e aulas-passeio sobre a "Percepção da Paisagem" por meio do antigo "Projeto Tudo em Volta", atual "Circulando Educação", da SEFP 8 Prefeitura Municipal de Santo André.

Apesar da grande proximidade, a Escola ainda não conhecia com profundidade a Praça Maria Quitéria e o Pesqueiro Girassol, tampouco desenvolvia atividades permanentes nessas áreas.

\section{Referências em paisagens fluviais}

\section{Parque Escola - poder público}

O Parque Escola, localizado em Santo André, foi idealizado pelo poder público para ser um espaço de difusão de idéias ligadas à botânica, meio ambiente, arte, cidadania e à paisagem urbana, principalmente. $O$ conceito de arquitetura utilizado pode ser considerado como "pedagogia da 


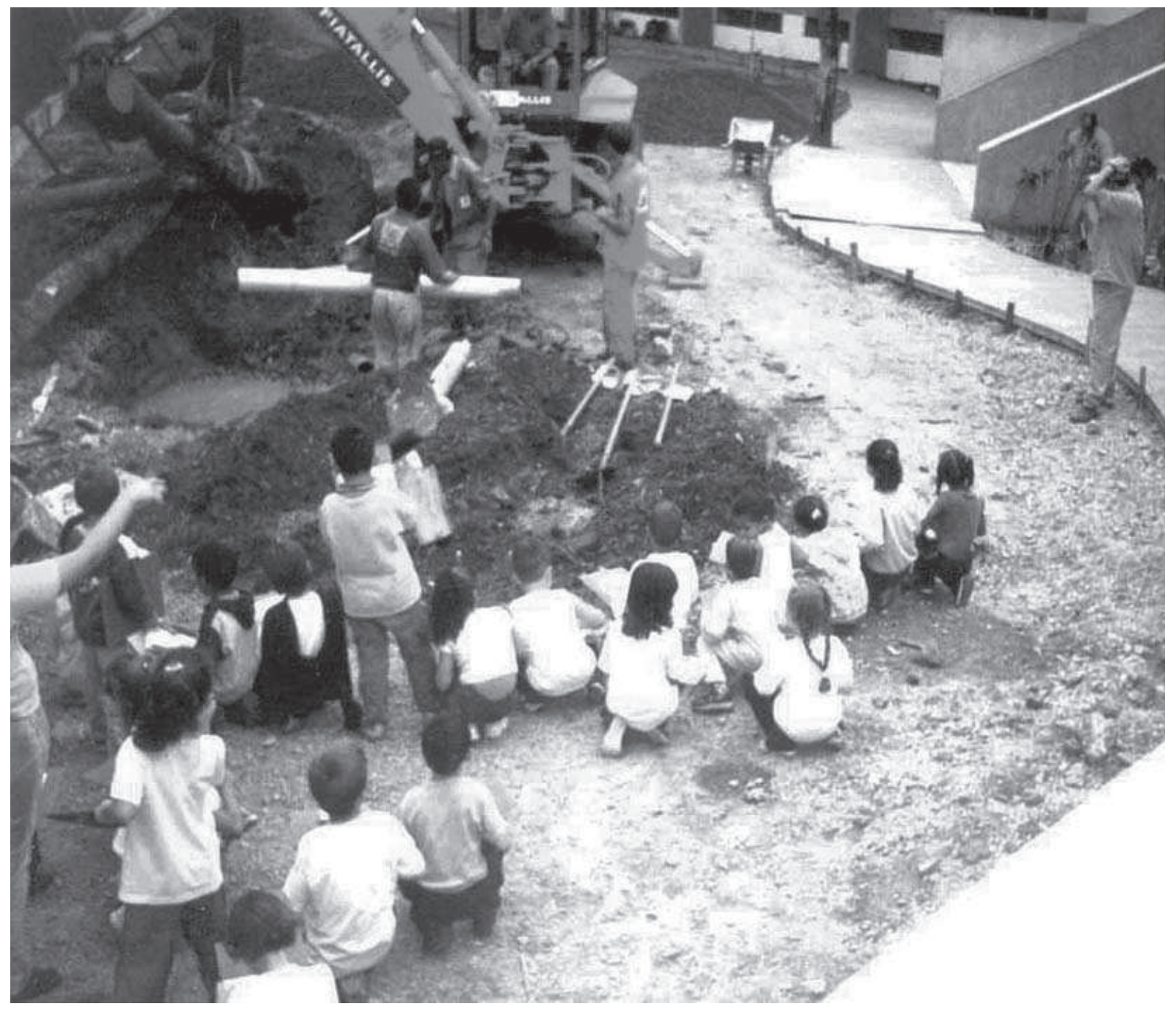

paisagem" por trabalhar com reutilização, reuso e reciclagem de materiais. A área localizada próxima ao Córrego dos Meninos abriga uma significativa coleção botânica e oferece diversos cursos e atividades gratuitas ligadas ao meio ambiente. Além de ser a sede do DPAV 9, o Parque também sedia diversos projetos da SEFP, principalmente o Projeto "Circulando Educação" (antigo "Tudo em Volta") que desenvolve diversas atividades, por exemplo, a "aula-passeio".

\section{Parque do Gato - setor privado e público}

Localizado na foz do Rio Tamanduateí, confluência com o Rio Tietê, São Paulo, o Parque do Gato foi projetado e parcialmente executado para requalificar a área que antes abrigava a Favela do Gato. Além disso, a área ainda abriga um Estádio de Beisebol, campos de futebol, áreas destinadas para a prática de sumô e gateball, galpões de escolas de samba, sede de associações e algumas construções irregulares. Muitos desses espaços serão relocados ou retirados do Parque.

O Parque foi idealizado pela COHAB - Prefeitura Municipal de São Paulo e projetado pela empresa Raul Pereira Arquitetos Associados. Além do Parque, a área abriga o Conj. Habitacional Parque do Gato com os antigos moradores da Favela do Gato. O conceito do projeto e a iniciativa de implantar este Parque potencializaram a Paisagem Fluvial Urbana, porém a falta de um processo participativo permanente colaborou para um processo de vandalismo crescente. 


\section{Parque do Cordeiro - ONG}

Localizado em São Paulo, o processo de viabilização desse Parque é uma referência de iniciativa da comunidade local, organizada por meio da ONG SAJAPE ${ }^{10}$ que acompanha minuciosamente todas as etapas para a implantação do Parque. Consciente dos direitos à cidadania, a ONG mobiliza ações para a defesa das áreas verdes e para a preservação das águas urbanas, como o Córrego do Cordeiro que passa dentro do Parque.

Entretanto, apesar dos esforços, o Parque está parcialmente executado e fechado para evitar vandalismo, enquanto aguarda sua conclusão que depende de verbas fragmentadas de TCAs ".

\section{Parque Pinheirinho d'Água - Universidade}

Este Parque é uma referência por causa da iniciativa da universidade, no caso a Pós Graduação da FAU-USP, e, sobretudo, do conseqüente envolvimento de algumas lideranças comunitárias nesse processo.

A iniciativa em transformar essa área com grande potencialidade hídrica em Parque foi de parte da comunidade local, que a defendeu de inúmeras tentativas de invasão. O Projeto do Parque, que se desdobrou num intenso processo de apropriação, foi iniciado numa disciplina da FAUUSP que utilizou a metodologia da "Charrette" 12. Essa técnica pretendia desenvolver projetos de paisagismo com a participação da população, por meio de quatro equipes interdisciplinares compostas por alunos e especialistas que apresentaram suas propostas às comunidades locais. Um projeto-síntese foi elaborado pela equipe do DEPAVE da Prefeitura Municipal de São Paulo e o projeto executivo foi terceirizado.

O Parque teve uma pequena área executada por meio de verbas de vários TCAs, mecanismos estes que não garantem um processo contínuo de implantação, muito menos de envolvimento e apropriação por parte das comunidades. Apesar das dificuldades, a FAU-USP e algumas lideranças comunitárias continuam acompanhando este processo em nome da defesa da Paisagem Fluvial local.

\section{Oficinas}

As atividades desenvolvidas foram aplicadas em diversos representantes dos Parques e Praças citados acima, bem com uma equipe interdisciplinar composta por: jornalista, pedagoga, técnico ambiental, arquitetos, biólogos, produtor de vídeo, além de representantes de diversas prefeituras, principalmente do DPAV e SEMASA ${ }^{13}$, de Santo André. Essa diversidade de participantes tinha como intuito estimular a "troca de saberes".

\section{Oficina do "Ver" - percepção da paisagem}

$\mathrm{Na}{ }^{a}$. Oficina, os participantes percorreram o Rio Tamanduateí de sua nascente à foz e coletaram diversas amostras de água para análise. O objetivo foi despertar a percepção da paisagem na escala metropolitana, compreender o todo para depois agir pontualmente, cada qual em sua comunidade.

Foi desenvolvida inicialmente uma apresentação geral dos participantes, seguida de atividades individuais que estimulavam o imaginário de como seria a nascente. Todos conheceram a nascente em Mauá. $\bigcirc$ ônibus seguiu pelas margens do Rio, enquanto alguns participantes davam depoimentos sobre suas experiências e as amostras de águas foram coletadas. O percurso foi todo comentado com esclarecimentos sobre história até chegar à foz do Rio, onde os participantes desceram para conhecer o Parque do Gato e ouviram os depoimentos de moradores do local. Enquanto coletávamos a amostra mais difícil devido à profundidade e largura do canal, 
observamos várias crianças que percorriam descalças as margens da Foz no trecho mais poluído do Rio, que segundo moradores ainda recebem banhistas desavisados quanto às graves doenças veiculadas em suas águas.

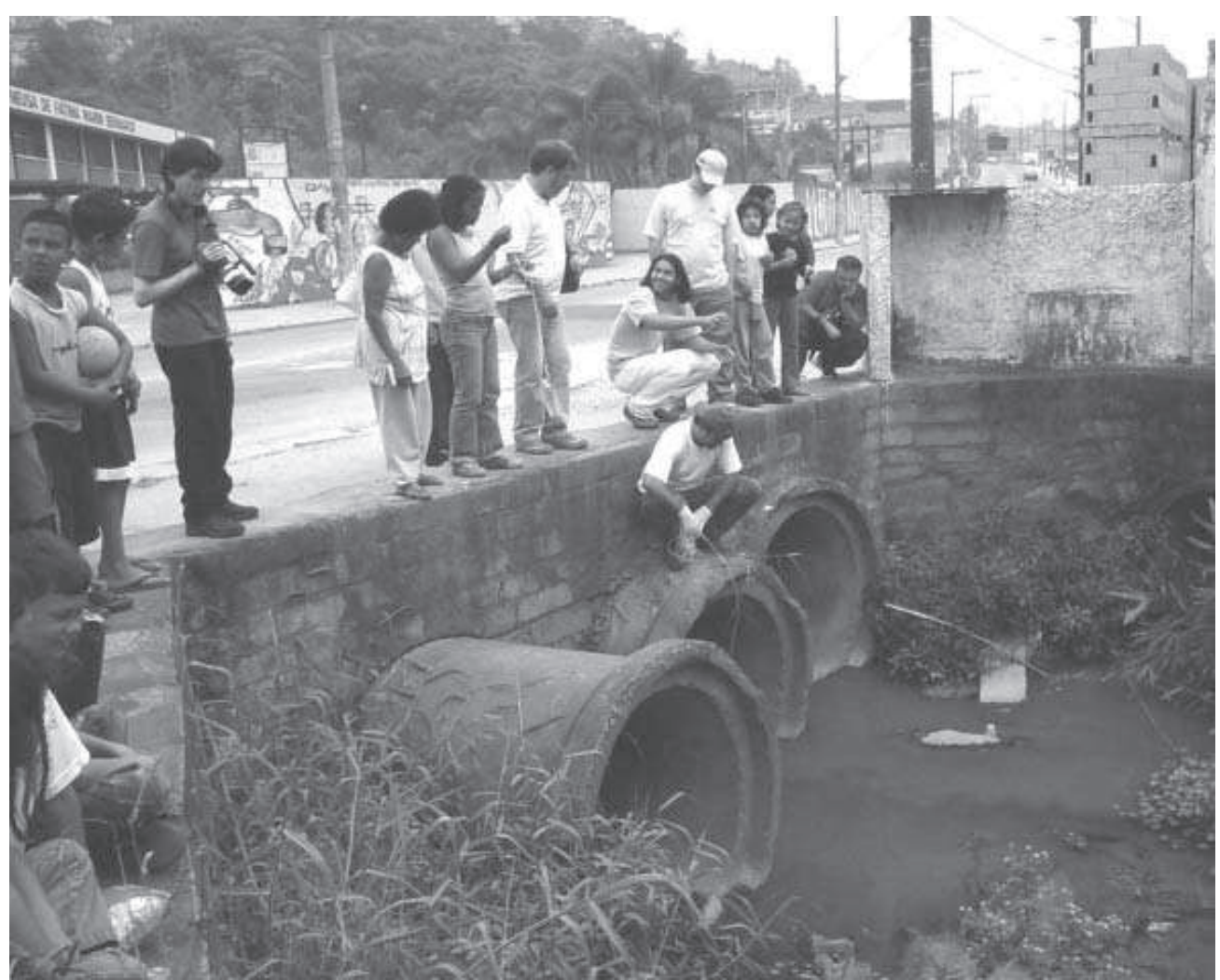

Figura 6: Oficina do "Ver": Polvição próxima à nascente do rio Tamanduateí - Coleta de água para análise Foto: Arquivo Daniela Ramalho, 2005

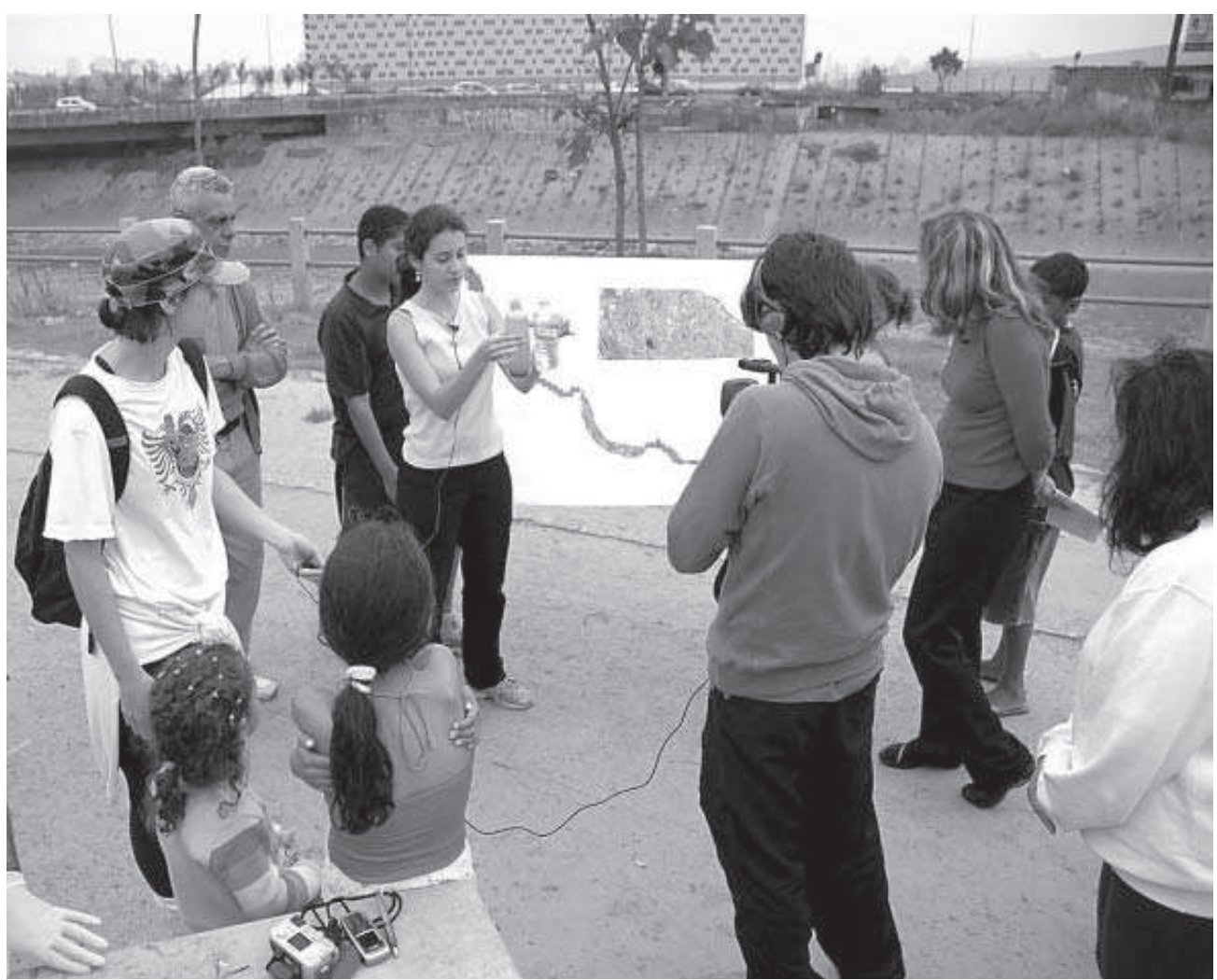

Figura 7: Oficina do "Ver": Polvição na foz do rio Tamanduateí, próximo ao rio Tietê - Coleta de água para análise Foto: Arquivo Daniela Ramalho, 2005 


\section{Oficina do "Sentir" - sensibilização da paisagem}

A segunda oficina tinha como objetivo sensibilizar os participantes com a vivência dos três estudos de caso citados (Praça Maria Quitéria, Pesqueiro Girassol e EMEIEF Camilópolis). A meta era proporcionar diagnósticos que mostrassem as potencialidades e vulnerabilidades dessas áreas de lazer.

Os participantes foram divididos em dois grupos, um para cada área de lazer. Cada grupo foi subdividido em quatro grupos temáticos que tinham como tarefa produzir relatórios de campo sobre:

- Flora e fauna;

- Recursos hídricos (coletas de água ${ }^{14}$, busca de nascentes e córregos ocultos);

- Aspectos positivos e negativos;

- Lideranças, captação de recursos, entorno e história.

Na seqüência, foi apresentada uma mini-palestra com um resumo de todo o material teórico produzido na dissertação. A partir daí, os participantes voltaram a se dividir e deram início à produção de diagnósticos com a utilização de fotos aéreas, livros sobre botânica, animais, história e a tradução de algumas palavras de origem tupi-guarani para a busca de significados nos nomes de córregos e ruas das áreas analisadas.

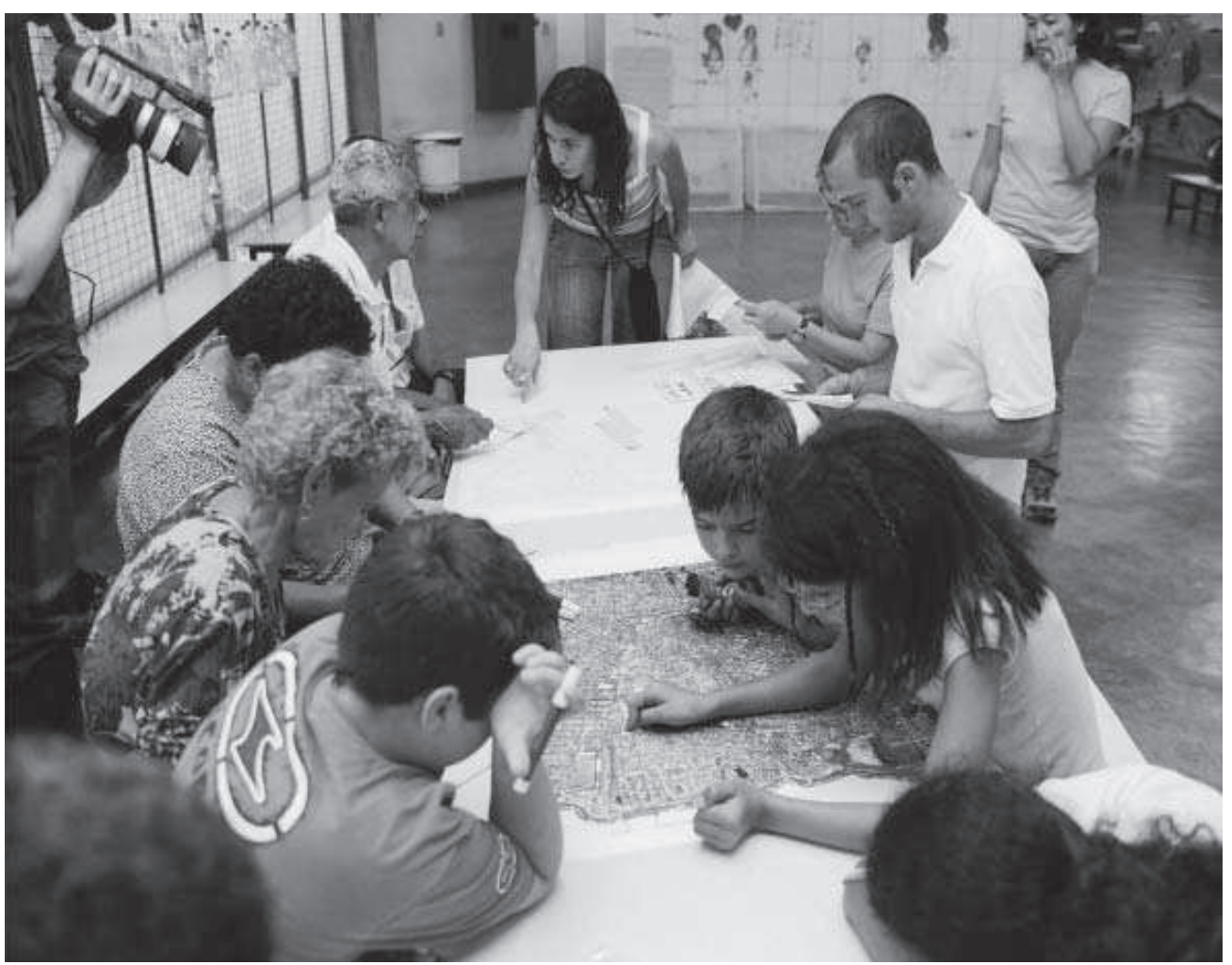

Figura 8: Oficina do "Sentir": Diagnóstico

Foto: Arquivo Daniela Ramalho, 2005

\section{Oficina do "Agir" - apropriação da paisagem}

A última oficina deu início a um estudo do meio no Parque Escola, seguida de uma "roda de conversa" a qual um representante de cada comunidade apresentava dificuldades em comum e exemplos bem sucedidos. Na seqüência, os participantes fizeram uma avaliação individual e se dividiram em dois grupos que deram continuidade aos diagnósticos e propostas para o desenvolvimento dos dois projetos coletivos de paisagismo para a Pça. Maria Quitéria e o Pesqueiro Girassol. Por fim, foram apresentados os resultados da análise de água e a proposta dos dois 
projetos. Finalmente, o grupo fez uma avaliação geral e encaminhou alguns desdobramentos para a continuidade do processo.

O objetivo dessa oficina foi propiciar subsídios e informações que colaborassem para a tomada de decisões, mobilização e um processo de gestão e apropriação que possibilitassem ações pertinentes e encaminhamentos coletivos.

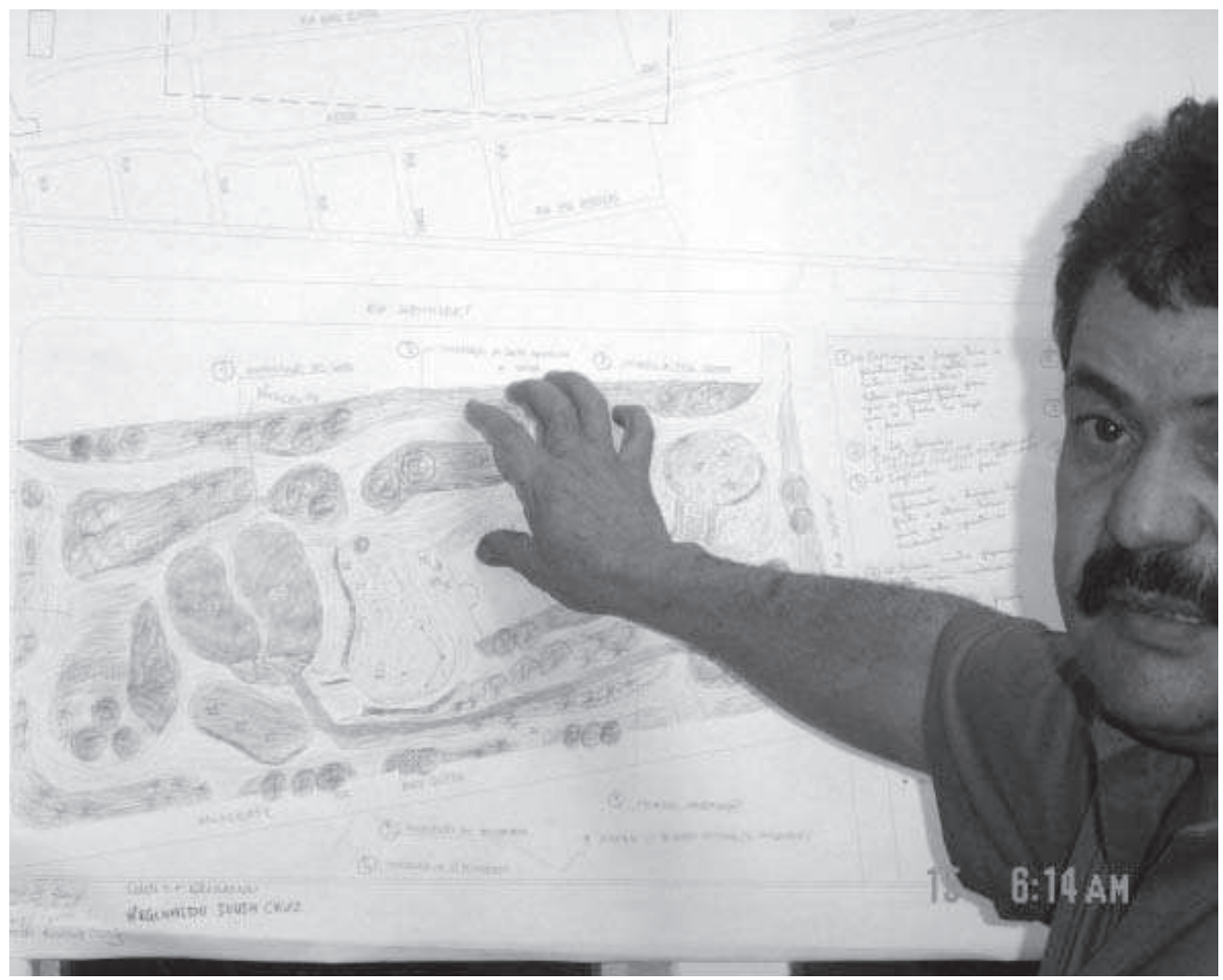

Figura 9: Oficina do "Agir": Propostas coletivas (projetos de paisagismo para as áreas de lazer próximas aos cursos d'água)

Foto: Arquivo Daniela Ramalho, 2005

\section{Desdobramentos}

Após as oficinas, a pesquisa procurou acompanhar os desdobramentos da pesquisa-ação. Podemos destacar alguns exemplos:

- EMEIEF Camilópolis: visita de pais e alunos na nascente do Rio Tamanduateí com aproximadamente 200 pessoas, coleta e análise de água de uma fonte no centro de Santo André como extensão prática do projeto desenvolvido em sala de aula.

- Pq. Pinheirinho d'Água: socialização da experiência vivenciada para alguns membros da Rede Municipal de Ensino da Prefeitura de São Paulo.

- SEMASA (Pref. Sto. André): Divulgação desta pesquisa num jornal de circulação interna.

- Pça. Maria Quitéria: ações de rearticulação das lideranças locais, mobilização e reunião com o governo municipal (DPAV - Pref. Sto. André) que se desdobraram na manutenção e reforma da Praça.

\section{Considerações finais}

A água é um bem inestimável. No entanto, muitas das Paisagens Fluviais metropolitanas têm sido desfiguradas e a participação da população na construção dessas paisagens tem sido uma 
necessidade. Essa pesquisa procurou formas para viabilizar essa participação e refletiu acerca da contribuição do arquiteto nesse contexto.

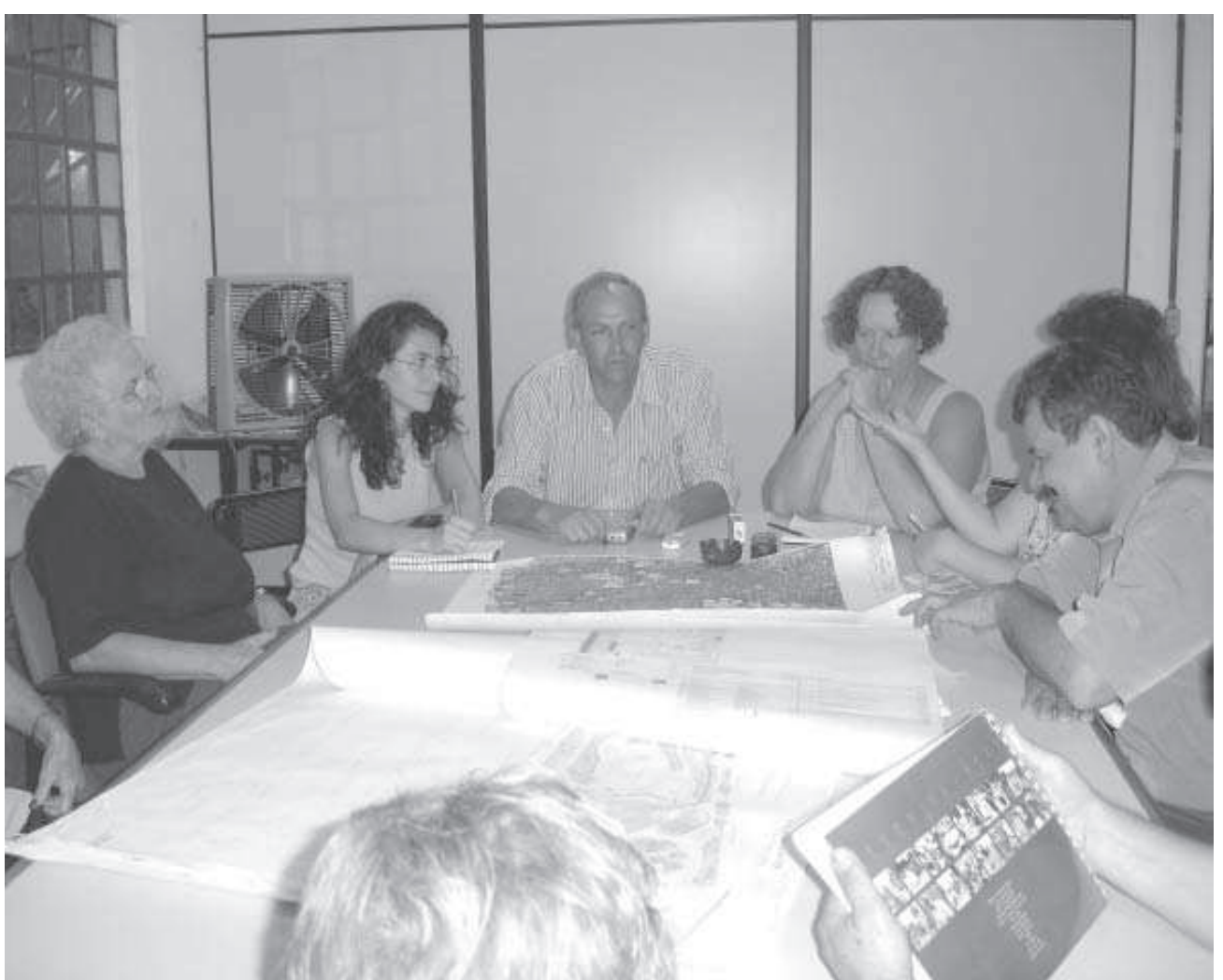

Figura 10: Desdobramentos: Reunião entre moradores do entorno da Praça Maria Quitéria e Diretoria do DPAV - Prefeitura Municipal de Santo André. Foto: Arquivo Daniela Ramalho, 2005.

Demonstramos que essas Paisagens Fluviais Urbanas apresentam muitas vulnerabilidades, mas também novas possibilidades de apropriação, por isso devem ser potencializadas.

Analisamos exemplos de algumas construções nas paisagens fluviais da RMSP. Constatamos que em sua maioria, foram construídas como espaços voltados para fins econômicos e assim se tornaram "não-lugares", pois carecem de um processo de identidade por parte de seus usuários que as transformaria em "lugar".

A pesquisa-ação desenvolvida se mostrou uma metodologia pertinente às expectativas desse estudo e viabilizou a contribuição prática da universidade e do arquiteto ao socializar a pesquisa teórica produzida e estimular a troca de saberes entre todos os participantes durante as oficinas. Os desdobramentos foram positivos, dentre eles destacamos a atuação das "escolas" e da Praça Maria Quitéria, onde houve uma motivação e mobilização da comunidade local que conseguiu reverter o quadro existente e viabilizar benfeitorias para a Praça junto à Prefeitura. Além disso, as comunidades compreenderam que a responsabilidade pela qualidade do espaço público não depende apenas do poder público, mas também da própria sociedade.

Para tanto, acreditamos que a contribuição do arquiteto paisagista, neste caso, é estimular e mediar um processo participativo ao fazer a síntese desse processo com o desenho. Porém, uma gestão eficaz depende do envolvimento das comunidades, de uma equipe interdisciplinar e principalmente da atuação do poder público.

O fato de acreditarmos na importância da inclusão de processos participativos não significa, todavia, que não devemos desenvolver reflexões e críticas sobre sua própria viabilidade. É notório que muitos exemplos de processos participativos por mais autênticos que sejam por parte da 
comunidade, não encontram garantias de continuidade por causa de conflitos com os órgãos governamentais e algumas vezes por causa de conflitos entre as próprias comunidades, o que sucumbi à ruptura do processo.

Por outro lado, podemos considerar que alguns projetos que não tiveram a presença intensiva da participação popular em seu processo inicial foram incorporados por grande parcela da sociedade, como por exemplo, o MASP, dentre outros.

É válido lembrar que esse estudo não pretendeu resolver a problemática apresentada e sim contribuir com a proposta de um método, capaz de ao menos sensibilizar as pessoas envolvidas no processo individual de tomada de consciência, que subsidiará um processo coletivo participativo de percepção e construção da paisagem urbana e da defesa das águas.

Esta pesquisa teve como objetivo refletir a respeito de possíveis estratégias de Construção Participativa na defesa das Paisagens Fluviais e na contribuição do arquiteto como mediador, capaz de realizar a síntese de processos sociais e ambientais, de forma a utilizar a arte como instrumento para o desenvolvimento de projetos que concretizem as expectativas dos usuários. Acreditamos que o arquiteto é um funcionário da cidade, por isso defendemos que para projetar a cidade é preciso exercitar a cidadania e que para melhorar a cidade é preciso convidar seus cidadãos.

\section{Notas}

(1) Tradução tupi-guarani. Ver bibliografia em (FERREIRA, M. F., 2004).

(2) Termo utilizado por (THIOLLENT, M., 2004) para uma pesquisa com desenvolvimento teórico e prático.

(3) Conceito desenvolvido pela Profa. Dra. Catharina Lima durante a disciplina "Estúdio da Paisagem - Charretel" (AUP 852) na Pós Graduação da Faculdade de Arquitetura da USP no 1o. Semestre de 2001.

(4) THIOLLENT, M., 2004, pg. 103.

(5) Conceito desenvolvido pela Profa. Dra. Catharina Lima durante a disciplina "Estúdio da Paisagem - Charrete I" (AUP 852) na Pós Graduação da Faculdade de Arquitetura da USP no 1o. Semestre de 2001.

(6) FREIRE, P., 2002, pg. 50.

(7) O termo "Córregos Ocultos" foi utilizado por Vladimir Bartalini em seu texto "Os Córregos Ocultos e a Rede de Espaços Públicos Urbanos" in Revista da Pós - FAU USP (Bartalini, V., 2005, pg. 82-96)

(8) SEFP - Secretaria de Educação e Formação Profissional da Prefeitura Municipal de Santo André.

(9) DPAV - Departamento de Parques e Áreas Verdes da Prefeitura Municipal de Santo André.

(10) SAJAPE - Sociedade Amigos dos Jardins Petrópolis e dos Estados (ONG)

(1 1) TCA - Termo de Compensação Ambiental

(12) Charrette - termo utilizado a partir de uma metodologia francesa para o desenvolvimento de projetos por meio de várias equipes interdisciplinares num prazo extremamente curto. Tal metodologia foi aplicada em algumas disciplinas da Pós-Graduação da FAU USP para o desenvolvimento de projetos em espaços públicos.

(13) SEMASA - Serviço Municipal de Saneamento Ambiental - Prefeitura Municipal de Santo André

(14) A análise da água foi feita a partir da metodologia, dos produtos e da orientação técnica fornecida pela empresa Policontrol, especializada nesses serviços.

\section{Bibliografia}

ADORNO, Vicente. Tietê: Uma promessa de futuro para as águas do passado. São Paulo: Cel Lep, 1999.

BARTALINI, Vladimir. Revista Pós, São Paulo: FAUUSP, 2003.

BOUCINHAS, Caio. Projetos participativos na produção do espaço público. 2005. Tese (Doutorado) - Faculdade de Arquitetura e Urbanismo, Universidade de São Paulo, São Paulo, 2005.

112 CADERNOS Lê Monde Diplomatique, n. 3, 2003.

DRISKELL D. Creating better with children and youth: A manual for participation. Paris: Unesco Publishing e Aarthscan Publication, 2002.

FERREIRA, Moacyr Costa. Dicionário morfológico tupi-guarani. 2. ed. São Paulo: Edicon, 2004. 
FERREIRA, Renata A. A anti-paisagem das fronteiras d'água: O rio Tamanduateí e sua relação com a legislação urbanística. 2002. Dissertação (Mestrado) - Universidade Federal de São Carlos, São Carlos-SP, 2002.

FREINET, E. Nascimento de uma pedagogia popular: Os métodos Freinet. Lisboa: Estampa, 1969.

FREIRE, Paulo. Pedagogia da autonomia: Saberes necessários à prática educativa. 25. ed., São Paulo: Paz e Terra, 2002.

FIX, Mariana. Parceiros da exclusão. São Paulo: Boitempo, 2001.

HARVEY, David. Condição pós-moderna. 13. ed., São Paulo: Loyola, 2004.

IDOETA, Irineu; IDOETA, Ivan V.; CENTRAL, Jorge P. (Orgs.). São Paulo vista do alto: 75 anos de aerofotogrametria. 1. ed. São Paulo: Érica Ltda, 2004.

PEREIRA, Raul Isidoro. Memorial de qualificação. 2003 Tese (Doutorado) - Faculdade de Arquitetura e Urbanismo da Universidade de São Paulo, São Paulo, 2003.

PIMENTEL, Maristela. A. A recuperação de rios degradados e sua re-inserção na paisagem urbana: A experiência do rio Emscher na Alemanha. 2003. Dissertação (Mestrado) - Faculdade de Arquitetura e Urbanismo, Universidade de São Paulo. São Paulo, 2003.

PRONSATO, Sylvia. Arquitetura e paisagem: Projeto participativo e criação coletiva, 1. ed. São Paulo: Annablume, 2005.

REBOUÇAS, A; BRAGA, B.; TUNDISI, J. G. (Orgs.). Águas doces no Brasil: Capital ecológico, uso e conservação. São Paulo: Escrituras, 1999.

SANOFF, H. Participatory design theory \& techniques. Carolina do Norte: Universidade do Estado da Carolina do Norte, 1990.

SANTOS, Magda. Águas revoltas - História das enchentes em Santo André. Santo André: SEMASA/Prefeitura de Santo André, 2002.

SANTOS, O. (Org.) Quando a rua vira casa. 3. ed. Rio de Janeiro: FINE/IBAM, 1985.

SHIMATANI, Yukihiro. Pequena história do desenho da paisagem de rios no Japão. Sukuba - Japão: Centro de Pesquisas em Engenharia Civil, Ministério de Construções, 1996.

SPIRN, Anne W. O jardim de granito. São Paulo: Edusp, 1995.

THIOLLENT, M. Metodologia da pesquisa-ação. 13. ed.São Paulo, Cortez, 2004. 